\title{
HEMORRHAGE AND POST-OPERATIVE OBSTRUCTION IN SUPRAPUBIC PROSTATECTOMY : AND AN OPEN OPERATION FOR THEIR PREVENTION.
}

\author{
BY .J. W. THOMSON WALKER, LONDON.
}

Trie operation of suprapubic prostatectomy described by Freyer in 1901 has stood the test of time, and is now universally practised. No certificate is required to prove its success either in regard to the low mortality in experienced hands, or in regard to functional results. It is of interest to note, however, that at St. Peter's Hospital 1276 cases of enlarged prostate have been operated on by this method since the first operation in 1901 up to the end of 1918 . Of these, 104 died ; a mortality of $8 \cdot 13$ per cent.

It is not my object in the following notes to decry a procedure so patently successful. My idea is that improvement may be made even in this successful operation, provided that the object of the variation is to meet some disadvantage, or untoward event, which is of more than accidental occurrence.

There are two occasional incidents in the operation of suprapubic prostatectomy that call for prevention rather than cure, and it is in order to meet these that the technique here described has been developed during the past four years. These incidents are : (I) Hamorrhage ; and (II) Post-operative obstruction; and I shall discuss each before turning to the preventive treatment.

\section{HAMORRHAGE.}

First, let us consider the question of hæmorrhage. I think that anyone who performs many prostatectomies must meet with cases of hæmorrhage severe enough to cause grave anxiety, and on very rare occasions to lead even to a fatal result. My experience in this respect does not, I believe, differ from that of others dealing with considerable numbers of such cases.

The frequency with which serious hæmorrhage occurs is difficult to state, for what may be counted a serious hæmorrhage in one patient may, from a more robust habit, or a greater resiliency, be looked upon as trivial in another ; and, moreover, it is easy to forget a successfully treated hæmorrhage in the rush of clinical work. A long period of immunity from such cases may give a false sense of security, which is suddenly dispelled by a series of anxious cases.

I estimate that 10 per cent of cases of suprapubic prostatectomy bleed severely, and that about 1 per cent have really serious hæmorrhage. The direct mortality of hæmorrhage is very small. I find only two cases in the statisties of St. Peter's stated as due to hæmorrhage. At the same time it must be remembered that loss of blood, while it is seldom the direct cause of death, is none the less a contributory, if not the deciding, factor in the cases that are certified as death from 'shock' (10 cases), 'cardiac failure' (9 cases), 'syncope' ( 3 cases), 'exhaustion' ( 7 cases) ; and its weakening effect must have at least some influence on the result in cases dying of 'asthenia,' or of pulmonary or bowel complications. In a long experience of suprapubic prostatectomy I have only had one death that $I$ ascribed as immediately due to hæmorrhage.

Hæmorrhage occurs at the time of the operation or at a later date. At the operation it may be troublesome from the start of the enucleation, and continue after enucleation is complete. On the whole, however, the cases that bleed early in the enucleation usually settle down very satisfactorily when the prostate has been removed. The worst cases 
of hæmorrhage at the time of the operation that I have met with were those where the enucleation proceeded with practically no hamorrhage. Then, when the operation was nearly over, hamorrhage commenced, and was severe and difficult to control. In these cases there was undoubtedly a considerable degree of shock with its attendant low bloodpressure during the enucleation, and a sharp reaction when the enucleation was completed.

It is not easy to say, before operation, which cases will bleed and which will not. A high blood-pressure naturally suggests the risk of hæmorrhage, and on the whole these cases bleed more frequently and more severely than those with a quiet soft pulse. A large succulent prostate is more likely to bleed than a smaller one. This is not, however, invariably the case. The largest prostate that $I$ have removed, and so far as $I$ know, the largest that has ever been removed, weighed $24 \mathrm{oz} .\left(1 \frac{1}{2} \mathrm{lb}\right.$.), and although the bleeding was free during enucleation, owing to my knife plunging into the great prostatic mass in opening the bladder, it settled down rapidly after enucleation, and gave rise to no trouble after the operation.

The following is a short note of this remarkable case :-

Case 1.--R. L., age 76, a patient of Dr. Pringle Morgan, of Seaford, had suffered from prostatic symptoms for twenty-five years, and had been completely dependent on the catheter for twenty years. No catheter less than 16 inches in length would draw the urine, and this only when pushed in until it almost disappeared in the urethra. For some years there had been difficulty in introducing the catheter, and on one occasion catheterization was impossible. He had lost flesh, and was subject to attacks of bronchitis, but his general condition was fairly good. The prostate felt from the rectum was very large and elastic, and filled the whole pelvis. I tied in a 16-inch catheter for a few days, but he became restless and uncontrollable at night.

On Dec. 6, 1918, the temperature was $101^{\circ}$, and I decided to drain the bladder suprapubically, and leave the enucleation to a later date. The bladder was distended with fluid and exposed. On incising the bladder wall, the knife plunged into the prostate, which rose well above the pubic symphysis. Bleeding was profuse and persistent, and I decided to remove the prostate at once. Owing to the size of the glaud, there was only just room to slip the fingers between the prostate and the brim of the pelvis, the bladder wall intervening. The gland shelled out readily, but it was necessary to split it in two in order to remove it from the bladder. Hamorrhage was very moderate during and after the enucleation. The cavity from which the prostate was removed was equal in extent to the cavity of the bladder. The bladder was drained with a large tube. The prostatic mass consisted of two large lobes with a fairly smooth outer surface. There was no indication of a medium lobe.

The following is a report by Dr. G. I. Eastes: "This enormous prostate weighed $1 . \frac{1}{2} \mathrm{lb}$, or 680 grms. Two large sections have heen cut, and they showed marked hypertrophy and hyperplasia of the gland alveoli. The structure is that of a simple adenomatous hypertrophy, and is innocent."

The patient bore the operation well, and the bleeding after the operation was very slight Bronchitis gave rise to a good deal of trouble, but the convalescence was otherwise uneventful.

A prostate subject to years of catheterization with an infected bladder, and a prostate where the bladder has previously been drained suprapubically, bleed, I believe, less severely after prostatectomy than a virgin prostate.

Reactionary hæmorrhage a few hours after the operation is probably the most common form of hæmorrhage. The patient is recovering consciousness after the anasthetic; he may be, and often is, restless; clots form in the bladder, causing severe spasmodic pain and straining, and are forced out of the large tube, and fluid blood or clots are projected along the urethra.

Serious hamorrhage at the end of a week or ten days may be due to sepsis, but it often results from over-exertion or straining on the part of the patient, from the rough. passage of the catheter along the urethra, or from the use of large enemata. The latter is, in my experience, one of the most frequent causes.

These hæmorrhages are all arterial, but a less acute although very persistent venous. bleeding with less clotting may occur, and is sometimes difficult to control.

Prevention and Treatment.-The measures for preventing and treating hæmorrhage in Freyer's technique consist in massaging the walls of the prostatic cavity with the finger after enucleation, and then irrigating the prostatic cavity and bladder with large quantities of hot weak silver nitrate solution; and to this may he added elevation of the foot of the bed on blocks. 
For all late hæmorrhages, that is, hæmorrhages occurring after the patient has been returned to bed, my practice has been to instal constant irrigation with weak silver nitrate solution, and continue this for several days. A catheter is tied in the urethra with the eye just inside the prostatic cavity. This is connected with a jacketed reservoir, a glass dropper being interposed, and the rubber supply-tube being conducted over a hot-water bottle to keep up the temperature of the fluid. The outflow from the bladder wound is collected by a Hamilton Irving suprapubic apparatus, and carried to a pail at the side of the bed. The flow is kept at a rapid drop. Should this fail, packing of the prostatic cavity is the next resort. An anæsthetic is usually necessary for this. A silk-wove catheter is passed along the urethra and pushed well into the bladder, and round this the prostatic cavity is packed. The right forefinger is introduced into the bladder through the suprapubic wound till the tip lies at the inlet of the prostatic cavity. Along this finger a long strip of two-inch iodoform gauze is passed by means of a curved instrument such as a uterine sound or a curved periosteum elevator. The gauze is packed into the prostatic cavity round the catheter, and pushed firmly in with the forefinger till the cavity is tightly filled. The large suprapubic tube is replaced, the foot of the bed raised, and a hypodermic injection of a quarter grain of morphia is given. The packing remains in place for from forty-eight to seventy-two hours. Before withdrawing it, the catheter should be drawn out until the eye lies in the packed prostatic cavity, and then a continuous stream of silver nitrate solution (1-15,000) started. This loosens the packing, and allows the withdrawal to be accomplished more easily. The iodoform gauze keeps quite sweet; in fact there is less tendency to infection and more rapid healing in these cases than in those where such treatment has not been necessary.

Hagner ${ }^{1}$ has introduced an indiarubber bag attached to the end of a rubber tube. The tube passes along the urethra, and the bag lies in the prostatic cavity. To produce pressure the bag is inflated through the tube and presses on the walls of the prostatic cavity. There is a tendency for the bag to float out of the prostatic cavity unless held firmly in position by some means such as continuous tension on the tube, but this gives rise to severe discomfort.

Soresi $i^{2}$ uses a similar bag with an additional tube which is brought out of the suprapubic opening. This he fills with mercury, which by its weight presses the bag more closely on the walls of the prostatic cavity and keeps it in position. Keyes ${ }^{3}$ passes a long Reverdin needle through the perineum into the prostatic cavity, through the torn edge at the bladder-neck on each side, and back again through the perineum. The ends of the suture are tied round a rubber tube on the perineum.

\section{POST-operative OBSTRUCtion.}

The operation of prostatectomy is performed for the relief of one or more of three conditions, viz., complete or partial retention of urine, prostatic irritation, hæmorrhage. It is a serious reproach to the surgeon if relief from these very obvious conditions is not obtained. I shall only discuss the first of these, namely, retention of urine.

Where the operation of prostatectomy has been performed, and the patient still has residual urine or complete retention, either: (1) The case operated upon has not been suitable for prostatectomy; or (2) The operation has been imperfect.

1. Cases which were Unsuitable for Prostatectomy.-This group comprises cases where there is atony of the bladder. There are two types of cases with atony of the bladder: (a) Cases where symptoms of organic disease of the spinal cord are present; (b) Cases where symptoms of nervous disease are absent.

a. Atony of the Bladder weith Nervous Disease.-The most obvious cases of bladder atony are those of organic disease of the spinal cord, of which tabes is the most frequent. There is not space here to deal fully with the question of prostatectomy in patients suffering from tabes, but passing notice must be taken of this subject. The mistake of attempting prostatectomy in a purely tabetic bladder, with the idea that the residual urine is due to prostatic obstruction, should never be made if the patient is fully 
examined before the operation. There are cases, however, where the symptoms of tabes are so slight and irregular that they may easily be overlooked. The absence of enlargement of the prostate felt by the rectum, the younger age of the patient, the absence of intravesical enlargement of the prostate on cystoscopy, and the typical atrophic trabeculation of the bladder wall, should lead to a careful investigation of the nervous system and prevent such a mistake.

At the same time the presence of tabes does not prevent the development of prostatic enlargement, and where the conditions are coincident, it is a very difficult problem to solve whether a residual urine, measuring, say, 8 or 10 ounces, is due to the atony of nervous disease or to obstruction.

Several factors will influence the decision. There is the time at which the bladder symptoms first appeared : if within the prostatic age (over 50), or prior to this. There is the absence or the prominence of bladder irritation, excessive irritation influencing the surgeon towards a diagnosis of prostatic cause, and complete absence of irritation indicating that the condition has a nervous origin. Neither is however conclusive, for the bladder in multiple selerosis is often of a spasmodic type, and cystitis in a tabetic bladder may produce frequent micturition or strangury; while the bladder subject to chronic prostatic obstruction may give rise to no discomfort or irritation. Finally, the type of the trabeculation, as seen by the cystoscope, may help : a fine atrophic type with widespread sacculation being specially associated with tabetic atony, and a thick fleshy type with obstructive retention.

Prostatectomy is not contra-indicated by the presence of tabes if the prostate is definitely enlarged, but the grave risk of leaving an atonic bladder after the operation must be carefully weighed. I have performed prostatectomy three times on patients the subject of advanced disease of the spinal cord-twice in tabes and once in multiple sclerosis-and in all with success, the vesical function being completely restored to its normal condition.

b. Atony of the Bladder without Nervous Disease.-Some years ago I described ${ }^{4}$ a group of cases, occurring most frequently in young men, where there was atony of the bladder without obstruction, and without symptoms of nervous disease. The group has not been widely recognized. The diagnosis is difficult. Early irregular tabes must be carefully excluded by lumbar puncture and other means, and contracture of the neck of the bladder and atrophy of the prostate must be searched for and excluded by thorough investigation. These cases are frequently diagnosed as stricture, and prolonged treatment for stricture in different hands of varied skill leads with certainty to injury to the urethra and sepsis, so that the cases ultimately become so complicated as to be hardly recognizable if the primary condition is not clearly impressed on the surgeon's mind by the study of virgin cases.

The recognition that such cases do exist appears to be dawning upon the profession, for here and there in the literature a reference to one may be found. Burns, ${ }^{5}$ in a recent article from the Brady Institute, Johns Hopkins University, states, “. There is a class of cases in which the cystoscopic and röntgenographic pictures arc absolutely typieal of disease of the central nervous system, but in which no evidence of such disease can be demonstrated clinically or serologically," without, however, referring to, or possibly being aware of, my original description. The differentiation of these cases is of extreme importance if an occasional disaster in the after-results of prostatectomy is to be avoided. They should be present in the mind of the surgeon whenever the symptoms of difficulty and chronic retention of urine are greatly in excess of the ascertainable urethral or prostatic obstruction, and where symptoms of nervous disease are absent.

2. Cases where the Operation has been Imperfect.-I pass now to post-operative obstruction following prostatectomy, the subject to which the above remarks are an introduction.

It is many years since I pointed out' that there were two danger-points for the development of stricture after prostatectomy, namely, at the membranous urethra where the mucous membrane is severed, and at the outlet of the bladder when the mucosa of the 


\section{SUPRAPUBIC PROSTATECTOMY}

bladder neck is torn across. It is very rare to find any tendency to contraction at the membranous urethra, partly, I believe, because it is the custom to pass the catheter in order to wash the bladder during convalescence.

At the entrance from the prostatic cavity into the bladder the danger of contraction is greater. In order to understand this, a glance at the anatomy of the vesicoprostatic opening is necessary.

The hypertrophied prostate enlarges in two directions, namely, into the bladder through the lumen of the vesical sphincter, and backwards outside the bladder, stripping the seminal vesicles and the fascia covering them from the bladder base. ${ }^{7}$ After enucleation of the prostate, the seminal vesicles, covered by fascia, form part of the posterior wall of the prostatic cavity, and the bladder base forms a canopy over the posterior part of the cavity, with an opening into the bladder situated well forward at the anterior limit of the cavity. The opening may not be very large at the time of the enucleation, and during the first fortnight the edges may gradually coalesce so that a complete canopy forms over the prostatic cavity, shutting it off from the bladder. Occasionally the lateral folds unite and produce the same result (Figs. $432 a$ and $b$ ).

It is easy to deceive oneself in passing a catheter in such a case, and to believe that the point of the instrument is in the bladder, while all the time it lies in the prostatic cavity, and is pushing up the canopy like a tent-pole. The visible effect of this on the convalescence is that the suprapubic wound does not heal, and a fistula forms. This is not the only cause of fistula after suprapubic prostatectomy, but it is one of them.

The fact that obstruction is taking place at the bladder outlet should be recognized at the time when the wound is nearly healed and a catheter is being passed. The want of freedom of the catheter point, the increasing difficulty in washing through the catheter and out of the wound, and the delay in healing of the wound, all point in this direction.

The obstruction may not be complete. It may be sufficient to prevent the catheter passing into the bladder, and to keep the suprapubic fistula open, but may still allow a little urine to pass into the urethra occasionally ; or, again, the urine passed may gradually diminish and ultimately cease.

If the condition is recognized in an early stage, it is easy to slip the finger along the partly healed wound and meet the tip of a catheter which is forced through the spot where the opening should be, now detected as a dimple or a bud of soft granulation tissue. A series of metal bougies of increasing size is passed, and then a large gum-elastic bougie tied in for a week or ten days. If, however, there is delay in recognizing the cause of the persistent fistula, a complete opening up of the bladder is necessary to correct the condition.

There is another condition causing post-operative obstruction which is more difficult to diagnose. A loose nodule (Fig. 433) or a flap of tissue (Fig. 434) plugs the entrance of the prostatic cavity, and causes intermittent obstruction. This may develop soon after the patient commences to pass water by the urethra. There is sudden obstruction, with pain and straining, and after a day or two a large slough, sometimes impregnated 
with phosphates, is passed, and micturition becomes free. In such a case it has probably been found that, with all possible care to prevent it, the bladder became infected, or, where infection previously existed, no amount of washing sufficed to clear it up. Then the loose flaps or masses of tissue have sloughed, but have eventually been passed, and the condition has been spontaneously cured.

In other cases the wound heals quickly after the operation, and the patient passes water well for a time. After a few weeks, intermittent difficulty begins to appear. In some cases a symptom which $I$ believe is typical of the condition develops. The act of micturition commences well, but, as it proceeds, difficulty develops and increases, and the stream falls away to a dribble, and may cease. 'The more the patient strains, the

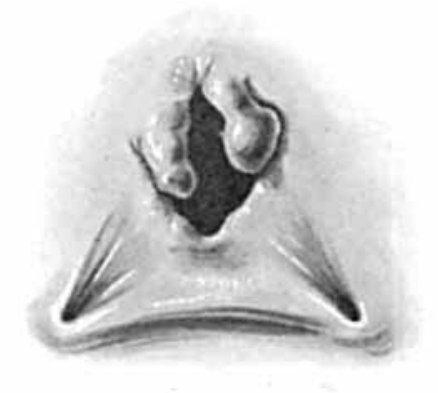

FIG. 453.-Nodules of prostatic tissue at the prostatovesical opening,

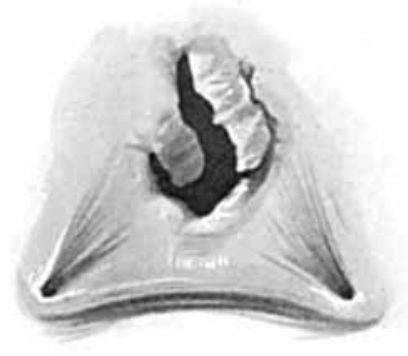

FIG, 434.- Strips of mucous membrane at the prostatovesical opening.

greater becomes the difficulty in discharging the urine. He soon learns that the best stream is obtained by avoiding all effort, and if possible checking any great rush of urine and reducing it to a moderate flow.

Sometimes an even more significant symptom develops. The patient can pass water freely while Iying on his back, but with great difficulty, or not at all, standing up. The wound may break down and a urinary fistula form, alternately healing and breaking down; but the scar may be proof against the intermittent obstruction, and remain firm. The passage of large metal instruments may improve micturition for a time, but it does not cure the valve action.

The following are two cases selected from a number that have come under my observation.

Case 2.-Rev. P. E. W., age 64, suffered from nocturnal frequency of micturition. The prostate was enlarged, and there were six ounces of residual urine. In November, 1917, the prostate was enucleated by a urinary surgeon. Urine commenced to pass by the urethra in three weeks. Catheters were passed, but there was difficulty in getting them into the bladder. The catheter was arrested at the entrance to the bladder, and the difficulty increased until the passage became impossible. The suprapubic wound remained open, and the urine passed partly by the urethra and partly by the fistula.

In February, 1918, the surgeon again operated. The bladder wound was opened up, and a catheter passed and tied in the urethra. The wound healed, but broke down again, and there were recurring periods of leaking from the suprapubic fistula. Micturition was performed with straining, and a catheter was passed with difficulty, the obstruction being at the neck of the bladder, as before. Sometimes the obstruction caused complete retention. The difficulty in passing urine was greater the more the bladder was distended. At night he could not pass water without introducing the catheter.

On April 29, 1918, I operated, removing the suprapubic scar and opening the bladder freely. The vesicoprostatic opening was a small aperture which gripped tightly a small curved catheter. It was surrounded by a thick cuff of hard fibrous tissue more prominent on the right side. The subjoining prostatic cavity was covered by a canopy of mucous membrane and fibrous tissue, and the urethral opening lay at its anterior margin. I cut away the whole of this, exposing the prostatic cavity, which was funnel-shaped. The bladder was drained. On May 10 the wound was nearly healed, and urine was passed partly by the wound and partly by the urethra. 
A catheter passed easily and without meeting any obstrurtion. In July, 1918, his doctor reported that he was perfectly well. The wound was firmly closed and micturition was normal. He has occasionally passed a little blood in the urine.

Case 3.-Canon H., age 71 , had suffered for some years from increasing frequency of micturition, and finally he had an attack of retention of urine, for which a catheter was tied in the urethra. The patient suffered from emphysema, bronchitis, and a dilated heart, and had glycosuria. On Jan. 14, 1918, his surgeon performed suprapubic prostatectomy. The prostate was large, and shelled out in one piece. There was difficulty in separation on the left side and posteriorly.

The after-treatment was conducted by the general practitioner. Progress was uneventful until, three weeks after the operation, the doctor attempted to pass a catheter and failed, and the surgeon was also unsuccessful. On Feb. 17 the suprapubic wound had nearly healed. The urine was ejected from the remaining fistula every two or three hours, but none passed by the urethra. Under an aniesthetic the surgeon introduced a finger into the bladder and passed a No. 10 urethral bougie through the urethra, and tied in a catheter. The catheter was retained in the urethra for fourteen days, when it slipped out and could not be replaced. On March 21 I examined him. The urine was discharged entirely by the suprapubic fistula, none passing by the urethra. A metal instrument was arrested at the entrance into the bladder. I opened the bladder freely, and found that the prostatic cavity was completely closed over by a thick membrane; no opening from the bladder into the urethra could be found. A metal bougie, passed along the urethra, raised up this canopy, and it was caught in a pair of vulsellum forceps and a picce cut out. The opening was then extended by cutting away the remains of the canopy, and a large opening leading from the bladder into the funnel-shaped prostatic cavity was obtained. A month later the suprapubic wound was healed and the urine passed naturally. About three months after the operation he died of cardiac failure, having continued to void his urine naturally till the end of his life.

\section{THE METHOD OF PREVENTION.}

Prevention lies in performing an open operation in which the bladder and prostatic cavity are fully exposed, the hæmorrhage is treated, and all nodules and strips of tissue and valves are removed.

Let me describe the operation in detail. A catheter is passed, and the bladder distended with 12 or 14 ounces of fluid. A free suprapubic incision is made, the bladder is opened, and the prostate enucleated with the gloved right forefinger, the gloved left forefinger in the rectum pushing up the prostate to aid the enucleation. The prostate being free in the bladder, the left forefinger is removed from the rectum, the glove is stripped from the left hand by a nurse, and the sleeve of the gown drawn up over the left elbow. The left forefinger, after plunging the hand into

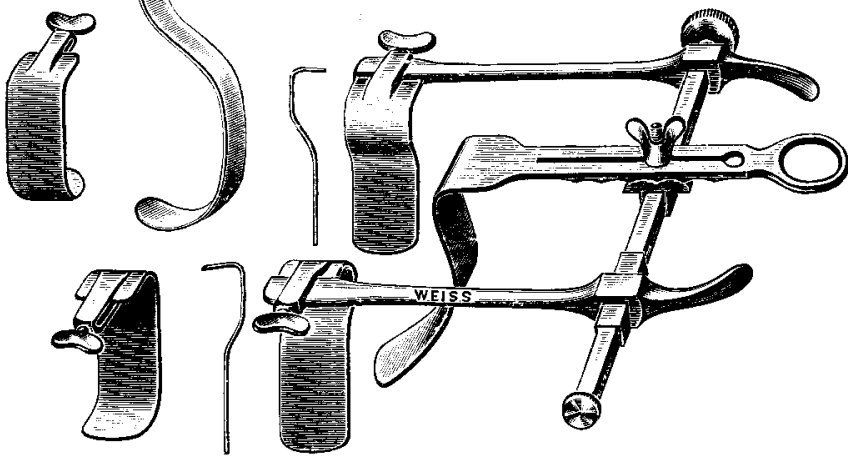

FIt, 435,-Author's bladier retractors. Abdominal frame with detachable bladder blades (shown also in profile) anil spatula for posterior wall. Hand retractor for anterior wall. Detachable abdcminal wall blades, biniodide solution, replaces the right finger in the bladder, and assists the removal, by ovum forceps, of the prostate from the bladder.

So far, except for the matter of gloves, the operation is that practised by Freyer. Now we depart from his technique. Instead of irrigating the bladder with hot solution, a catgut stitch is passed through each lip of the bladder wound, and the patient is placed in the full Trendelenburg position. A

good head-lamp is essential for this part of the operation. I then introduce my bladder retractors (Fig. 435). A gauze swab is pushed into the prostatic cavity to control bleeding temporarily, and the bladder is emptied of clot. When this is done, VOL. VII. - NO. 28. 
the plug is removed, and a careful inspection of the prostatic cavity and its inlet into the bladder is made (Fig. 436).

Hæmorrhage first claims attention. In some cases, by the position of the patient and the temporary plugging, the hæmorrhage has already been reduced to a very small amount of venous oozing, and it may be that no special measures are required to control bleeding.

In most cases, however, some amount of bleeding is in progress, and spouting arteries are seen in some. The bleeding is of two kinds, arterial and venous, and these can be

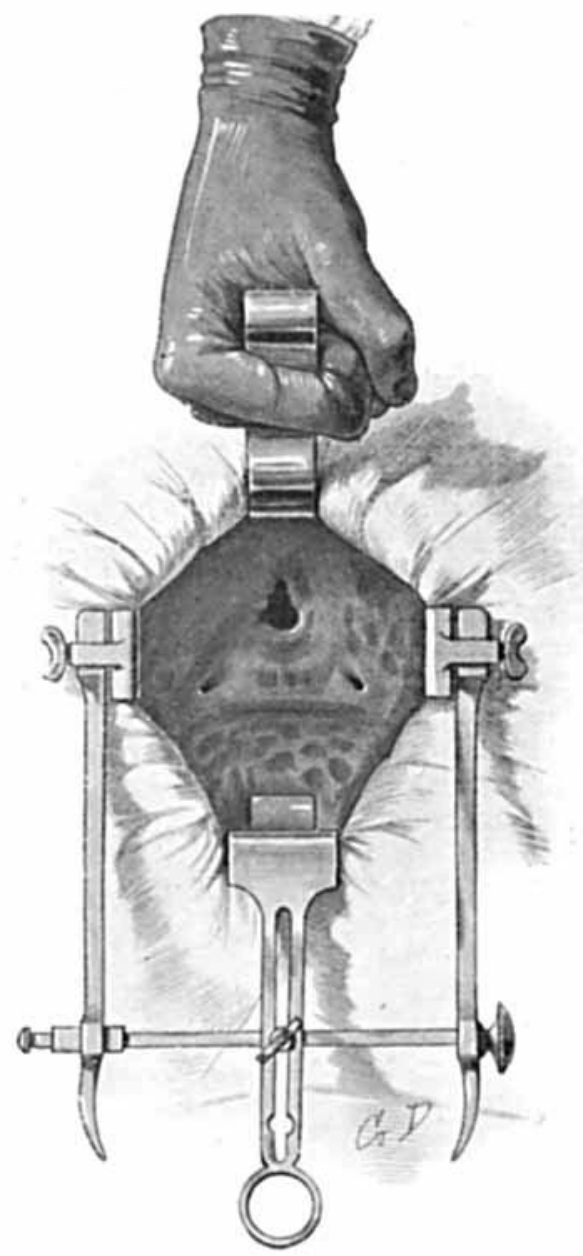

FiG. 436.---Vicw of the bladder and resicoprostatic opening, with retractors in place. clearly distinguished. Arterial bleeding comes almost invariably'from an artery situated at the brim of the vesicoprostatic entrance slightly behind the mid-coronal line. There is usually a spouting vessel on each side in this position (Fig. 439). This artery surrounds the neck of the bladder, and can frequently be felt in a normal bladder beating against the finger at the internal meatus when the finger is introduced. It might be named the cervical artery of the bladder. It is found spouting at the brim of the prostatic cavity just below the mucous membrane. Long Spencer Wells forceps are placed on these vessels. With my handled bladder-needle, a catgut stitch is passed through the mucous

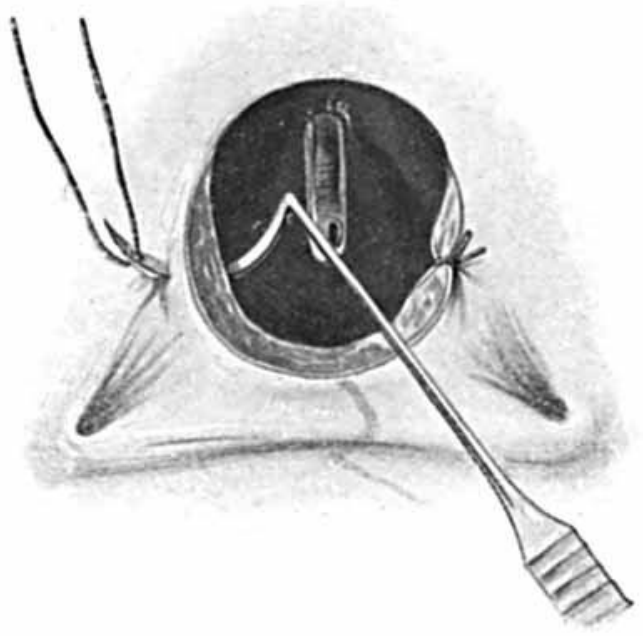

FIG, 437,-Introduction of hrmostatic stitches at brim of prostatic cavity.

membrane of the bladder and the sphincter, or what remains of it, appearing in the prostatic cavity below the brim. This is passed anterior to the forceps and tied, and the forceps removed. A second hæmostatic stitch is passed on the other side of the cavity (Fig. 437 ). 'These two sutures now act as tractors to pull up the neck of the prostatic cavity and keep the walls of the brim apart. Arterial bleeding from the wall of the cavity may be seen, but is not frequent. Venous hæmorrhage may be copious. Spencer Wells forceps are applied to any bleeding points, or, better, Moynihan's rather heavy artery forceps with 
curved beak are applied, and the tissue in their grasp crushed. This bleeding comes, as would be expected, mostly from the anterior wall of the prostatic cavity.

It is well to remember that the venous system of the prostate commences in the dorsal veins of the penis, which pass under the pubic arch and, gaining size, up the anterior surface of the prostate in the middle line between the layers of the sheath. This vertical limb splits at the base of the prostate to form two arms of a $Y$ which pass on in either side of the prostatic base at its junction with the bladder.

It is from the vertical limb of this $Y$ that the venous bleeding comes, and if copious it is checked by plugging the prostatic cavity with gauze for a few minutes. It seldom gives rise to much trouble, and a certain amount of venous oozing may be neglected. In two cases when the venous bleeding from this source appeared threatening, I pushed the anterior wall of the bladder backwards, and stripped the anterior wall of the prostatic cavity from its light attachment to the back of the pubic symphysis, and then, with one of my long-handled bladder needles, passed a catgut stitch transversely through the wall of the prostatic cavity, and tied it so as to compress the vertical limb of the prostatic plexus. No ill effects, such as cedema of the penis, followed this manœuvre, and $\mathbf{I}$ should repeat it if serious venous hæmorrhage made it necessary. In practically all cases it is sufficient for the arterial bleeding to place a hæmostatic stitch in each side at the brim of the prostatic cavity and to plug the cavity temporarily. Sometimes these may be omitted and the crushing of the artery forceps relied upon to control the bleeding. In exceptional cases, I have had to plug the prostatic cavity with gauze (iodoform gauze in two-inch strips is the best for this purpose) when very severe hæmorrhage was in progress and it was impossible to see any single point of bleeding. This is very easily and accurately accomplished when the interior of the bladder is fully displayed with the retractor in place. The cavity is packed around the catheter, which is still in place and which projects well into the bladder cavity. The rest of the operation is finished as usual, and the plugging removed at the end of forty-eight or seventy-two hours.

Having controlled the hæmorrhage by suture as above, the next point to attend to is the removal of tags, flaps, strips, or nodules, in order to avoid post-operative obstruction or valve formation. A large variety of these occur. It is a revelation, when one comes to examine the prostatic cavity after enucleation of the prostate, to see the number, size, and variety of these loose masses of tissue. The following may be found :-

1. Strips and flaps of mucous membrane. At the vesicoprostatic opening there is frequently a large loose flap of mucous membrane on each side, and these flaps may almost meet over the prostatic cavity (Fig. 432). The flaps are loose and can be pushed aside. A long strip of mucous membrane sometimes lies loose at the anterior lip of the opening (Fig. 434).

2. Nodules of prostatic tissue in the neighbourhood of the opening (Fig. 433). These may be present even where the prostate has apparently shelled out cleanly.

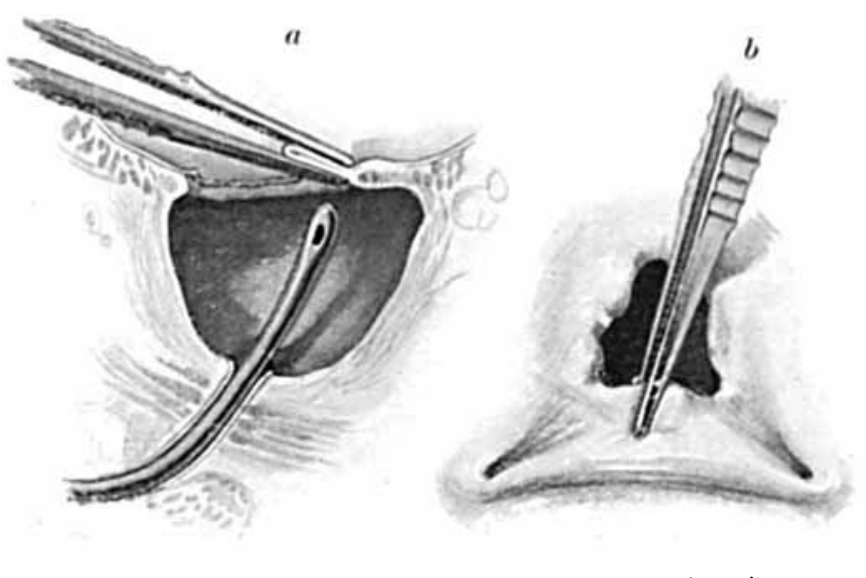

FIG. 438.-Canopy overhanging posterior part of prostatic cavity. (a)_Sagittal section; (b) View from bladuer aspect.

3. A prominent semilunar ledge forming the posterior lip of the opening. This tends to reduce the lumen, and occasionally causes complete occlusion of the orifice. This ledge is formed by the trigone and adjoining base of the bladder, and is produced by enucleation of the part of the hypertrophied prostate which extends backward beneath the bladder base (Fig. 438, $a, b$ ). 


\section{THE BRITISH JOURNAL OF SURGERY}

4. Loose strips of prostatic capsule, and occasionally small nodules of gland tissue, attached loosely to the wall of the prostatic cavity (Fig. 439).

5. Long loose strips of urethral wall pulled out and torn across.

All loose tags, shreds, and semi-detached nodules of prostatic tissue tend to slough, and are ready soil for the growth of bacteria. Where they do not slough they may form valves and obstructions, and cause intermittent or continuous obstruction. All these are carefully clipped away, and the mucous membrane is trimmed at the edge of the cavity.

A word must be said in regard to the fold lying at the posterior lip of the prostatovesical opening. This is picked up on the middle line by forceps (Fig. 438), and a wedge with its base forwards cut out of it with long curved scissors (Fig. 440). The tissue removed

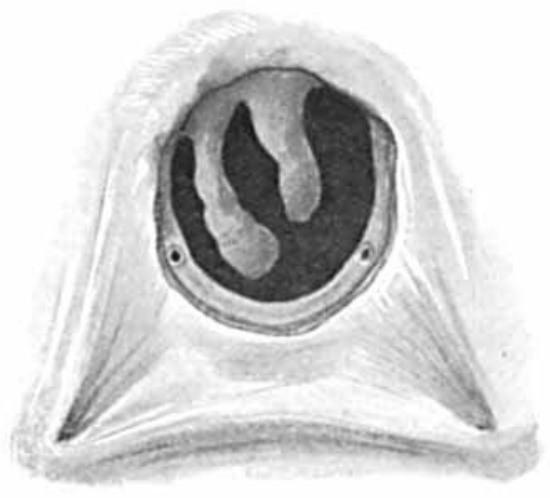

FIt. 439.-Ioose strips of prostatic capsule bangin: from wall of prostatic cavity. Note the two vessels on posterior ledge.

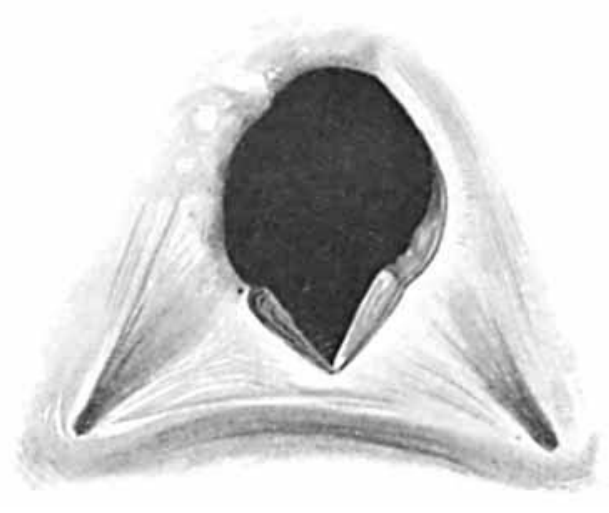

Fic. 440,--Prostatovesical opening with wedge cut in posterior fold.

consists of mucous membrane, trigonal muscle, and frequently some gland tissue. This effectually removes any possibility of narrowing of the vesicoprostatic opening.

In 1904 I pointed out ${ }^{8}$ that the action of the internal vesical sphincter was destroyed in cases of suprapubic prostatectomy for enlarged prostate. This is partly effected by the prostate pushing its bulk through the sphincter into the bladder and expanding it, and partly also, no doubt, by the further stretching effected during the enucleation. The sphincter action is taken up by the compressor urethra, which effectually prevents the escape of the urine. The prostatic cavity thus forms a prolonged neck communicating with the bladder cavity. After prostatectomy, a catheter passed along the urethra is frequently held up by this canopy, and the opening into the bladder may only be found by exploring forward with the point of the instrument. The posterior lip of the opening is formed by a hard fibrous sickle-shaped fold, while the anterior bladder wall passes into the prostatic cavity almost without a ledge to mark the junction. By cutting a wedge out of this sickle-shaped canopy at the time of the operation, subsequent occlusion of the orifice is prevented.

Having completed the clearing out of the prostatic cavity, and the enlarging of the vesicoprostatic opening, repair of the bladder and abdominal wall is undertaken.

I still consider that free drainage is essential to the success of the operation, and use the large (1 inch) rubber tube introduced by Freyer. The bladder retractors are removed and the blades changed for retraction of the abdominal wall. These blades are inserted in the pubic end of the wound with the framework now at the kneeward side of the operation field (Fig. 441). The bladder is pulled up by the catgut slings which are still in place, and the rubber tube carefully placed so as to reach, without pressing on, the base of the bladder. By traction on the slings, the wound in the bladder wall is freely exposed, 
and is closed up to the tube by interrupted catgut sutures. Care is taken to avoid stitching the bladder wall too tightly round the tube, as this would cause post-operative spasm. of the bladder. The slings are removed, and the bladder drops down into the pelvis. A small rubber tube is placed in the prevesical space, and the two tubes are clipped and held up while the abdominal wall is repaired. I place two catgut mattress sutures through the recti and sheath about an inch on each side of the wound, and unite the margins of the anterior rectus sheath with a continuous catgut suture. The mattress sutures are then tied and the skin united.

After-treatment. - When the patient has come round from the anasthetic, a Hamilton Irving suprapubic box is applied, and he is propped up in bed.

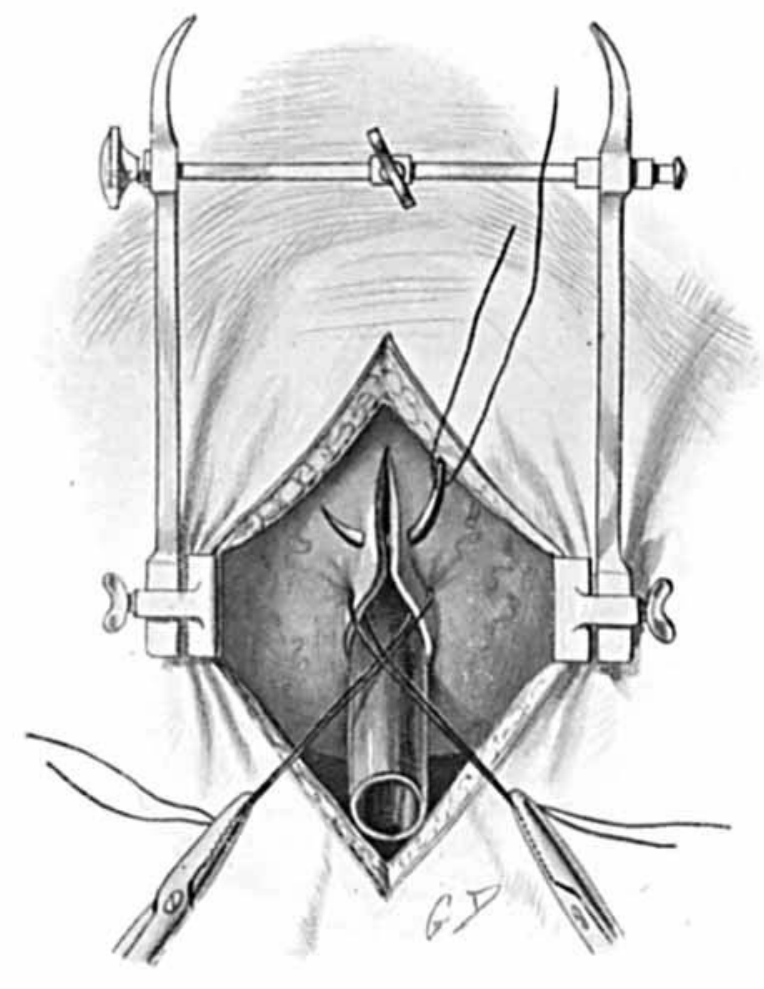

FIf. 411.-Retraction of abdominal wall; closure of bladder wound.

If there has been severe bleeding during the operation, and the prostatic cavity has been packed, the catheter will have been left in the urethra. If there is any suspicion that bleeding may recur, or if the bladder is the seat of chronic infection, the catheter is tied in without packing. Continuous irrigation (silver nitrate solution 1-15,000) through the catheter may be instituted, and is equally serviceable for commencing hæmorrhage or for chronic sepsis. It may be continued for four or five days, or even longer if necessary. Continuous irrigation is an excellent method of cleaning a septic bladder, and prevents further infection. The suprapubic wound heals quickly and cleanly under the treatment. It has the disadvantage of immobilizing the patient, and is very irksome to some individuals. The tubes are removed on the fifth completed day. Enemata should be avoided as far as possible. 
COMMENTS.

1. Two objections may be raised to this operation. It requires a longer incision than the usual prostatectomy, and more time is required for its performance.

2. The longer incision suggests the possibility of a hernia of the scar; but hernia depends upon the ability of the surgeon to repair the abdominal wall and to keep the wound clean.

3. The incision should heal up to the tube channel by first intention, and the wound in my cases is firm and strong. With an efficient system of repair of the abdominal wall, a hernia need not be feared.

4. The length of time spent on the operation from start to finish is about thirty minutes, and I have seen no increase in the shock after the operation. Shock in prostatectomy is partly due to hæmorrhage and partly to rough handling in enucleation. Both of these causes can be avoided in this open operation.

5. An unexpected feature of the open method is the absence of a great part of the spasmodic pain after the operation. This pain, which lasts for twenty-four or forty-eight hours, is due partly to the large tube, but mostly to the accumulation of clots in the bladder, with consequent spasm of the bladder muscle in the attempt to expel them. 'The latter factor is abolished where the blceding can be efficiently combated.

\section{REFERENCES.}

1 Hagner, Jour. Amer. Med. Assoc., 1914, Dec. 19, 2218, and Surg. Gyn. and obst. xix, 555.

2 Soresi, New York Med. Jour., 1919, July 12, 51.

3 Keyes, Jour. Amer. Med. Assoc, 1914, Dec. 19, 2217.

${ }^{4}$ 'Thomson Walker, Annals of Surg., $1910,577$.

5 Burxs, Surg. Gyn. and Obst., 1917, June, 659.

6 Thomson Walker, Brit. Med. Jour., 1905, Oct. 7, 1250.

7 Thomson Walker, Med. Chir. Irans., 1904, lxxxvii, 404.

8 Thomson Walker, Jour. Anat. and Phys., and Trans. 2nd Congress Internat. Assoc. Urology, London 1911 . 